\title{
Modular tapered conical revision stem in hip revision surgery: mid- term results
}

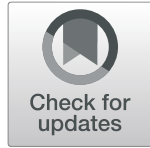

Loris Perticarini ${ }^{1}$, Stefano Marco Paolo Rossi ${ }^{*}$ (D), Alberto Fioruzzi ${ }^{2}$, Eugenio Jannelli ${ }^{3}$, Mario Mosconi ${ }^{3,4}$ and Francesco Benazzo ${ }^{1,4}$

\begin{abstract}
Background: The aim of this paper is to evaluate the clinical and radiological outcomes of a fluted tapered modular distal-fixation stem at medium to long-term follow-up. The hypothesis of this investigation was to verify if the use of this implant design may have provided potential advantages in femoral revisions and post-traumatic instances where the restoration of the anatomy was the prime concern.

Methods: We retrospectively reviewed 62 cases of femoral revision surgeries, performed in Paprosky type IIIA and IIIB bone defects between January 2001 and December 2011 with a mean follow-up of $8.5 \pm 1.5$ years (range 5.1 15.9 years) where a modular fluted stem was used. The clinical assessment was performed with the Harris Hip Score $(\mathrm{HHS})$, and the radiographic evaluation was carried in order to assess the stability of the femoral component. Intraoperative and postoperative complications were recorded, and the rates of complications and revisions for any cause were determined.
\end{abstract}

Results: Mean HHS improved 35.4 points from the preoperative assessment. Radiographic evaluation showed a stable stem anchorage in $90.3 \%$ of the cases at the last follow-up. Five (8\%) implants required additional surgery. Neither breakage of the stem nor loosening of the taper junction were recorded. Kaplan-Meier survivorship was 89.4\% (Cl: 88.8-90\%) for any complication and 92.3\% (Cl: 91.8-92.7\%) according to revision for any causes at 81 months follow-up.

Conclusions: Our findings suggest that this stem design is a reliable option in cases of complex femoral bone defects, as well as in cases with high functional deficiencies, with promising survivorship.

Keywords: Conical revision stem, Femoral bone defects, Hip revision surgery, Modularity, Periprosthetic femoral fracture

\section{Background}

An increase in the number of revision surgery is expected over the next few decades with a growing number of primary total hip joint replacements in younger and more active patients $[1,2]$.

Revision surgery aims to create a stable construct, protect bone and soft tissues, fill bone defects, and restore

\footnotetext{
* Correspondence: rossi.smp@gmail.com

${ }^{1}$ Sezione di Chirurgia Protesica ad Indirizzo Robotico - Unità di Traumatologia dello Sport, U.O. Ortopedia e Traumatologia Fondazione Poliambulanza, Via Bissolati 57, 25124 Brescia, Italy

Full list of author information is available at the end of the article
}

the biomechanical function of the hip. Femur reconstruction during a revision total hip arthroplasty can be the most challenging phase of the operation [3]. Bone defects may be the results of osteolysis, infection, periprosthetic fractures, stress shielding, and implant extraction. The several classifications for the femoral bone defects proposed in the literature are treatment oriented, guiding the surgeons in selecting the right method for femoral reconstruction [4].

Cemented long femoral stems are usually indicated in elderly patients who present the most severe conditions

(C) The Author(s). 2021 Open Access This article is licensed under a Creative Commons Attribution 4.0 International License, which permits use, sharing, adaptation, distribution and reproduction in any medium or format, as long as you give appropriate credit to the original author(s) and the source, provide a link to the Creative Commons licence, and indicate if changes were made. The images or other third party material in this article are included in the article's Creative Commons licence, unless indicated otherwise in a credit line to the material. If material is not included in the article's Creative Commons licence and your intended use is not permitted by statutory regulation or exceeds the permitted use, you will need to obtain permission directly from the copyright holder. To view a copy of this licence, visit http://creativecommons.org/licenses/by/4.0/ The Creative Commons Public Domain Dedication waiver (http://creativecommons.org/publicdomain/zero/1.0/) applies to the data made available in this article, unless otherwise stated in a credit line to the data. 
in terms of bone quality. Cementless monolithic revision stems can be used but sometimes they may have limits. Cementless modular revision stems differ from the first two as they allow independent preparation of distal and proximal bone in the femur, as well as individual adjustment of leg length, offset, and anteversion. Fluted tapered stem designs are indicated when it is necessary to achieve axial and rotational stability distally in the femur because the proximal part can't support fully the vertical load [5].

Although several authors have reported mid-term survival rates higher than $95 \%$, there is still a lack of studies detailing the role of vertical stem instability in the osseointegration of fluted tapered stems [6-8]. This study aims to evaluate the clinical and radiological outcomes of a fluted tapered modular stem with distal fixation at a minimum follow-up of 5.1 years. Primary hypothesis of this investigation was that this implant could show clinical outcomes and survival rates at least comparable to those presented in previous studies with cemented or uncemented monoblock or modular stems. Secondary hypothesis was that this stem is reliable in cases of periprosthetic femoral fractures, septic or aseptic stem loosening with femoral bone defects type IIIA and IIIB according to the Paprosky classification. Finally we wanted to verify the hypothesis that the use of this implant design may provide potential advantages in the cases of femoral revision and post-traumatic instances where the restoration of the hip anatomy was the prime concern.

\section{Methods}

Between January 2001 and December 2011, 101 patients underwent a hip revision arthroplasty using a fluted tapered modular stem (Revision Stem, LimaCorporate, San Daniele del Friuli, Italy).

14 patients died before the end of the 5 years evaluation; 25 patients were not reachable for different reasons, related to distance and unavailability for changing the address. Thus, the final study group consisted of 62 patients (Table 1), with an average follow-up of $8.5 \pm 1.5$ years (range 5.1- -15-9 years). There were 25 males (40.3\%) and 37 females (59.7\%) with a mean age of $69 \pm$ 12.27 years (range: 29-89 years) (Table 2). 38 cases (62.2\%) required an associated cup revision. In 29 cases (76.3\%), we used a standard acetabular cup (2 cases Blind Cup ${ }^{\circ}, 16$ cases Delta TT cup ${ }^{\circ}$ and 11 cases Trilogy TM cup ${ }^{\circ}$ ). In 9 patients (23.7\%) was necessary to use an acetabular revision system (5 cases Delta TT revision cup $^{\circ}$ and 3 cases SPH Revision ${ }^{\circ}$ ). The tribology used was polyethylene-ceramic in 25 cases, polyethylene-metal in 10 cases and ceramic-ceramic in 3 cases.

Indications for revision were aseptic loosening of the implant in $38(60.7 \%)$ hips, septic loosening in 5 (8.2\%), periprosthetic fracture in $11(18.0 \%)$, mechanical failure (implant breakage) of the component in 7 (11.5\%), and failure of internal fixation of proximal femur fracture in 1 case (1.6\%). The femoral bone loss in septic and aseptic loosening cases was classified according to the Paprosky classification as IIIA (91.9\%) and IIIB (8.1\%) [9].

A single senior surgeon performed all the revision procedures using a posterolateral approach. In 49 (79\%) cases a transfemoral osteotomy was used to remove the previous stem, and in 6 (9.7\%) of these cases a circular osteotomy was associated. The decision to use a transfemoral osteotomy in the majority of cases was dictated by the good fixation of the implant in the majority of the cases, and by the features of Revision stem that is conical and doesn't follow the anterior bowing of the femur; the femoral canal is, therefore, easier to prepare with this approach.

The osteotomy fragment was secured after reimplantation with at least two cerclage wires in all cases. A prophylactic cerclage wire was placed in all cases of transfemoral osteotomy, and before the insertion of the stem into the femur with thin cortices in order to prevent the propagation of intraoperative cracks.

All patients were intravenously administered antibiotic prophylaxis using $1 \mathrm{~g}$ of Vancomycin during surgery and $500 \mathrm{mg}$ every $4 \mathrm{~h}$ until the second day after surgery, while thromboembolism prophylaxis was performed using Enoxaparin $4000 \mathrm{UI} /$ day for 30 days after surgery.

Table 1 Flowchart of selected patients

101 patients subjected to revision with stem revision

- 14 died before 5 years evaluation for causes unrelated to the surgery

- 15 refused to come and check because they lived too far away

- $\quad 10$ were not contactable due to a change of telephone number or address

62 patients remained are underwent to clinical and radiologic investigation 
Table 2 Demographic data, diagnosis and Paprosky bone defect classification

\begin{tabular}{lllll}
\hline & Minimum & Maximum & Mean & Std. Deviation \\
\hline Age $(\mathrm{y})$ & 29 & 89 & 69.02 & 12.275 \\
Weight $(\mathrm{kg})$ & 30 & 97 & 68.81 & 14.501 \\
Height $(\mathrm{cm})$ & 120 & 184 & 165.66 & 10.070 \\
& & $\mathrm{~N}$ & $\%$ & \\
Sex & Female & 37 & 59.7 & \\
& Male & 25 & 40.3 & \\
Side & Left & 29 & 46.8 & \\
& Right & 33 & 53.2 & \\
Diagnosis & & N. & & $\%$ \\
Aseptic loosening & 38 & & 60.7 \\
Septic loosening & 5 & & 8.2 \\
Periprosthetic fractures & 11 & & 18.0 \\
Mechanical stem failure & 7 & & 11.5 \\
Femoral nail failure & 1 & & 1.6 \\
Femoral bone loss & Paprosky & & $\%$ \\
& IIIA & & 91.9 \\
\hline & IIIB & &
\end{tabular}

All patients were allowed to stand on the second postoperative day and to progress to full weight-bearing with crutches as tolerated. Clinical and radiographic evaluations were carried out before surgery, as well as at 6 weeks, and at 3, 6 and 12 months after the surgery, and then at 1-year intervals until the final follow-up visit. Clinical assessment was comprised by a detailed medical history, a physical examination, and the Harris Hip Score [10]. Femoral component stability was determined using the criteria described by Engh et al. [11]. Subsidence of the femoral component was measured as the change in the distance from the center of the femoral head to the most proximal point on the lesser trochanter. Heterotopic ossifications were evaluated according to the Brooker classification [12].

Statistical analysis was performed using the IBM SPSS Statistics for Macintosh (Version 22.0, IBM, Armonk, NY, USA). At the minimum follow-up of 63 months, we calculated the rate of complications and of revisions for any cause using Kaplan-Meier methodology.

\section{Description of the implant}

The tapered fluted modular Revision (Lima Corporate, San Daniele del Friuli, Italy) stem is made of titanium alloy Ti6Al4V and has a straight distal anchoring module of conical shape (with a $1^{\circ} 36^{\prime}$ angle). The body lengths are either 140 or $200 \mathrm{~mm}$, with $14-26 \mathrm{~mm}$ in diameter ( $1 \mathrm{~mm}$ increments), with eight longitudinallyoriented anchoring blades. A Morse taper (which is deflected by $4^{\circ}$ from the long axis of the distal part) ensures the assembly of the distal and proximal elements of the stem; a locking screw provides an additional safety tool to guarantee a stable connection of the two parts. The proximal module is available in 7 sizes $(50-110 \mathrm{~mm}$ long with $10 \mathrm{~mm}$ increments), with a neck-shaft angle of $131^{\circ}$ ( $40 \mathrm{~mm}$ offset) and $135^{\circ}$ (35 mm offset) and a $12 / 14$ neck cone. The vertical stability is based on the tapered shape of the body, while longitudinal blades ensure rotational stability.

\section{Results}

At the last follow-up, the mean Harris Hip Score was $72.1 \pm 15.8$ (range: $23-97$ ), with an average improvement of 35.4 from the preoperative score, which showed a mean value of $36.7 \pm 12.4$ (range: $5.8-54$ ). $33.9 \%$ of the patients ( 21 cases) had good or excellent results, $27.4 \%$ (17 cases) had fair results, and 38.7\% (24 cases) had results under 70 points.

At a mean follow-up of $8.5 \pm 1.5$ years (range 5.1- - 15 9 years), five (8\%) patients required additional surgery. Two (3.2\%) patients had a traumatic periprosthetic fracture at 6 and 8 years follow up and were treated with open reduction and internal fixation. Three $(4.8 \%)$ patients underwent surgery for an acetabular cup failure due to liner wear. One (1.6\%) patient had an episode of dislocation and experienced reduction under anesthesia. One $(1.6 \%)$ patient had a wound infection treated with oral antibiotics. Therefore, no revision was performed in this study for a mechanical failure of the implant. Seven (11.3\%) patients developed heterotopic ossifications: four (6.5\%) cases were classified as Brooker II, two (3.2\%) as Brooker III and one (1.6\%) as Brooker IV.

At the last follow-up, 56 (90.3\%) cases showed radiographic evidence of a stable bone fixation (Figs. 1-2). In one $(1.6 \%)$ case, the formation of a pedestal was observed, while in two (3.2\%) cases, the appearance of

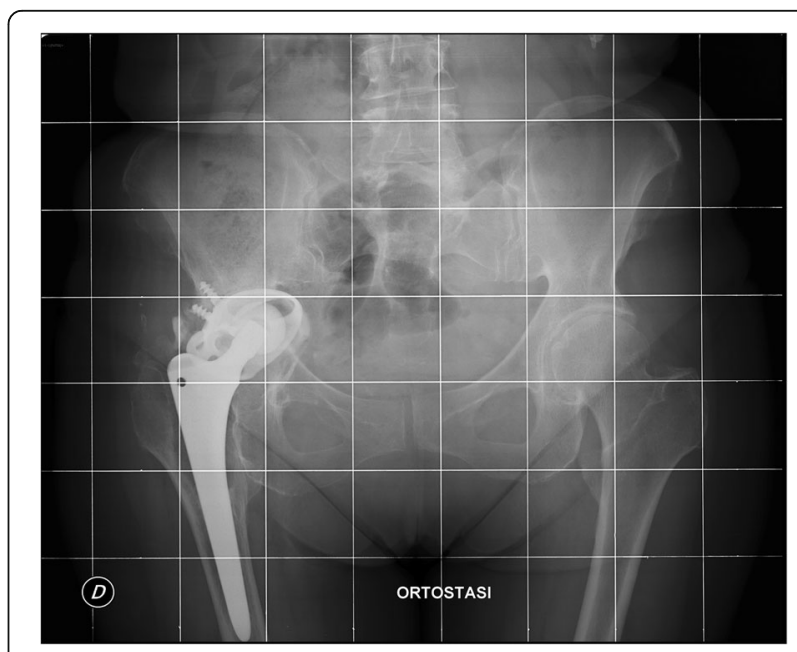

Fig. 1 X-ray of aseptic loosening of right hip of 54 years old female 


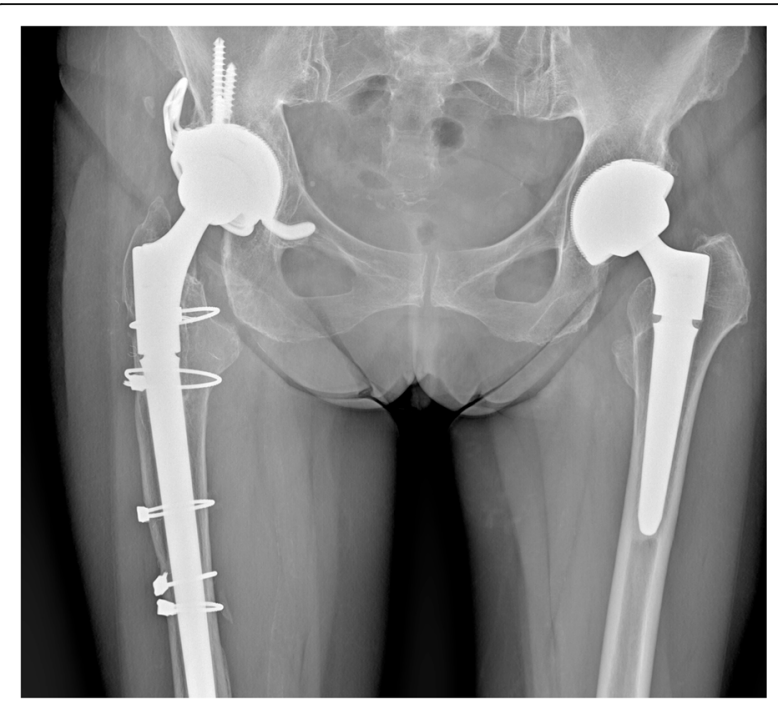

Fig. 2 X-ray at 7 years' follow-up after revision surgery

radiolucent lines surrounding the implant interface was noted.

Early (within 3 months of surgery) subsidence ( $>2$ $\mathrm{mm})$ of the stem occurred in $4(6.5 \%)$ cases: one $(1.6 \%)$ stem subsided by $2 \mathrm{~mm}$, one (1.6\%) by $3 \mathrm{~mm}$, one (1.6\%) by $4 \mathrm{~mm}$, and one (1.6\%) stem by $6 \mathrm{~mm}$, with a measured mean value of $3.8 \mathrm{~mm}$ (range: $0-6 \mathrm{~mm}$; SD: 1.7 $\mathrm{mm}$ ). After the subsidence was first observed, none of these 4 hips showed any further signs of progression at subsequent follow-up.

\section{Intraoperative complications}

In four (6.5\%) cases, an intraoperative femoral fracture with diaphyseal split occurred, one proximal and three distal. Two of the four diaphyseal split fractures occurred during stem insertion, whereas the other two occurred during cement removal. All the diaphyseal split fractures were treated with plate and cerclage wires and subsequently healed in situ with stable bone fixation of the stem. One additional (1.6\%) anterior cortical perforation occurred during stem insertion; due to patient's comorbidity and the poor functional request it was decided to treat it conservatively. All the fractures eventually healed without any further intervention and went on to stable bone fixation of the stem. In two cases (3.2\%), there was a leg length discrepancy less than $1.5 \mathrm{~cm}$ that proved not correctable with the revision procedure.

\section{Survival analysis}

Kaplan-Meier Survivorships has been assessed for the final study group of 62 patients reaching a maximum period of 15.9 years, and we decided to exclude the patients died with the implant in situ. Considering complications for any cause as the endpoint, the survival rate was $89.4 \%$ (CI: $88.8-90 \%)$ at 6.75 years. When taking as an endpoint revision for every cause, the survival rate was $92.3 \%$ (CI: $91,8 \%-92,7 \%)$ at 6.75 years, as shown in Table 3. The survival curve for both analyses reached the lowest rate at 6.75 years, as showed in Figs. 3 and 4.

\section{Discussion}

The conical stems with fins conceived by Wagner to address femurs with a failed prosthetic stem, work bypassing the proximal portion of the femur (usually affected by variable bone loss, deformity or fracture). The load is transmitted to the femoral diaphysis, with an initial mechanical fixation both axially and rotationally. A secondary osteointegration occurs, and the design has shown to provide early repair of proximal osteotomies and pre-existing fractures.

Modularity of the proximal portion has been added to satisfy the unmet needs coming from the second generation of Wagner type stems (monoblock). The concept of the stem adopted in this series is based upon the possibility of fitting the stem as distal as needed, in the portion of bone where fixation is optimal, and to reconstruct the proximal portion with the length of body needed, form $50 \mathrm{~mm}$ to $110 \mathrm{~mm}$. The potential advantage of using modular distal-fixation stems is that the modularity facilitates the intraoperative adjustment of the leg length, femoral offset, and neck version [13]. This main feature is coupled with the possibility of optimizing the version of the neck, and therefore theoretically reducing the incidence of dislocation.

In the existing literature, there are conflicting opinions regarding the clinical efficacy of stem modularity in revision THA. Regis et al. [14] analyzed the rate of dislocations in two groups of patients undergoing THA revision with standard-modularity stem and an increased-modularity stem; the authors reported that dislocations were observed early in both groups, and concluded that the use of an increased-modularity revision stem alone did not prove to be effective in reducing the risk of postoperative dislocation. A retrospective analysis of 145 hips undergoing revision, showed at 2 years follow-up no statistically significant difference in complication rates (intraoperative fracture, dislocation and aseptic loosening), functional outcomes, and radiographic parameters both in modular and monoblock splined, tapered titanium stems [15]. However, this study presents a limitation, consisting in a limited number of patients with severe degree of femoral bone loss (grade IIIB and IV) treated with femoral monoblock stem, and therefore the two groups are not fully homogeneous. Regis et al. [16] in their retrospective study of 68 consecutive hip undergoing femoral revision using a cementless monoblock stem, reported seven intraoperative fractures of greater trochanter; furthermore, eight 
Table 3 Survivorships for complications and revision for every cause

\begin{tabular}{lllc}
\hline & & Statistic & Std. Error \\
\hline Survivorship for Complications for every cause & Mean & 0.89450 & 0.003143 \\
& $95 \%$ Confidence Interval for Mean & Lower Bound & 0.88822 \\
Survivorship for Revision for every cause & & Upper Bound & 0.90078 \\
& Mean & & 0.92337 \\
& $95 \%$ Confidence Interval for Mean & Lower Bound & 0.91892 \\
& & Upper Bound & 0.92782 \\
\hline
\end{tabular}

stems (19.5\%) showed subsidence $\geq 10 \mathrm{~mm}$ and four dislocations within the first 24 days of surgery $(9.7 \%)$. On the other hand, the short-term results using tapered fluted modular distal-fixation stems have been good, with mechanical failure rates ranging from 1.4 to $4.3 \%$ at 2.3 to 4.0 years of follow-up $[17,18]$. In the study by Park et al. [19] no femoral re-revision was performed because of mechanical failure of the stem in the 62 hips at 4.2 years of follow-up. The mean stem subsidence was $1.1 \mathrm{~mm}$, and the complications included intraoperative diaphyseal split fractures (6\%), cortical perforations (6\%), and dislocations (5\%). We have indeed obtained a satisfactory result from this point of view, given the small number of stems that have undergone a distal migration and only one case of dislocation. All cases showing a distal migration were treated with the first version of Revision stem, where the diameter was set to steps of $2 \mathrm{~mm}$, and therefore anchorage and fitting was in these cases suboptimal. Our results are comparable with those of previous studies, reporting on considerable improvements in component fixation with no increase in the complication rates using a modular fluted and tapered grit-blasted stems [20]. It should be noted that the $1.6 \%$ rate of dislocations in this study is lower than recently reported dislocation rates ranging from 5\% using the same stem [19] to 7.4\% [21] or 8.4\% [22] in large cohorts of revision THAs with monoblock stems. We believe that the possibility to optimize the biomechanical

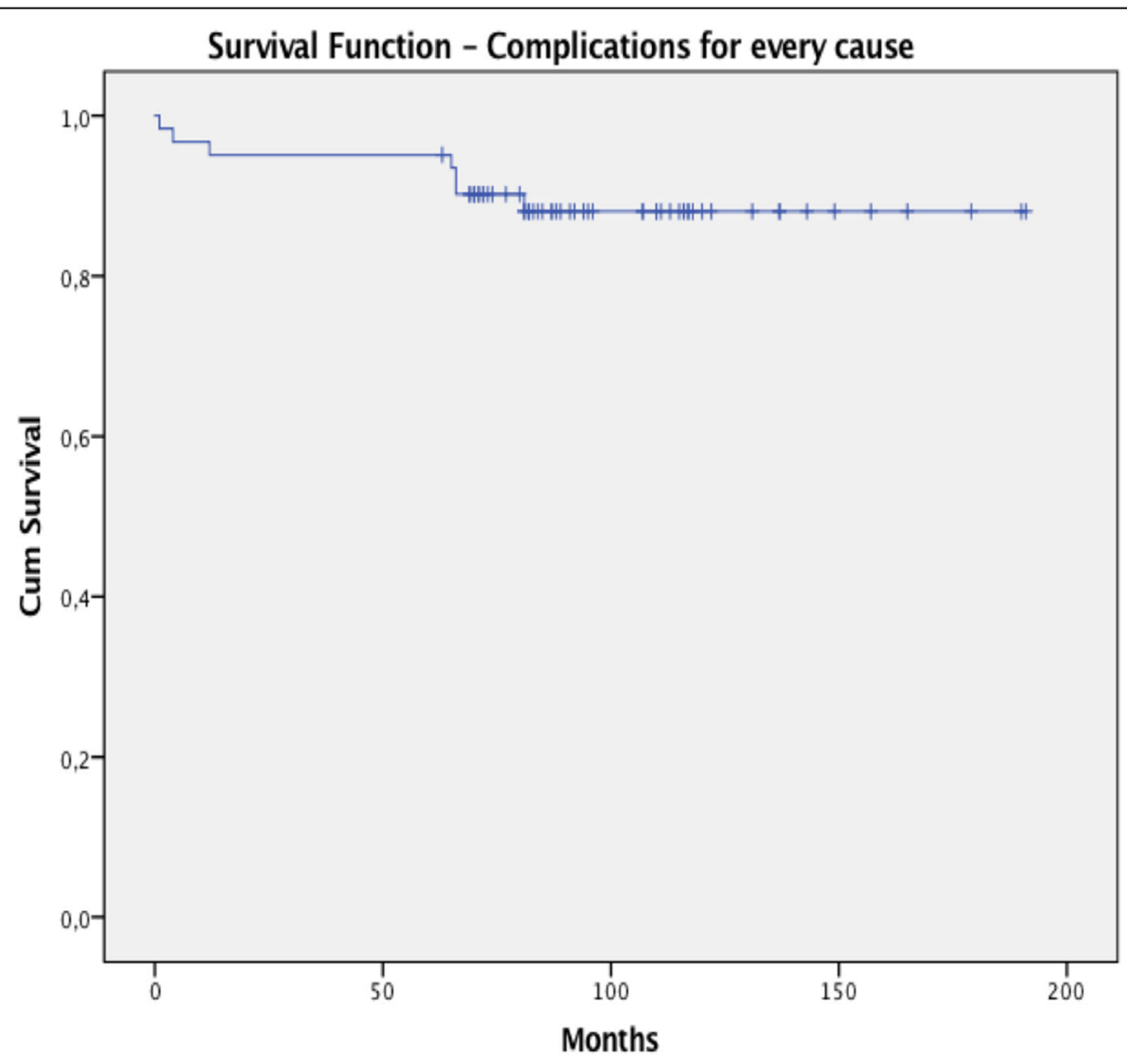

Fig. 3 Kaplan-Meier survival rate for complications for every cause 


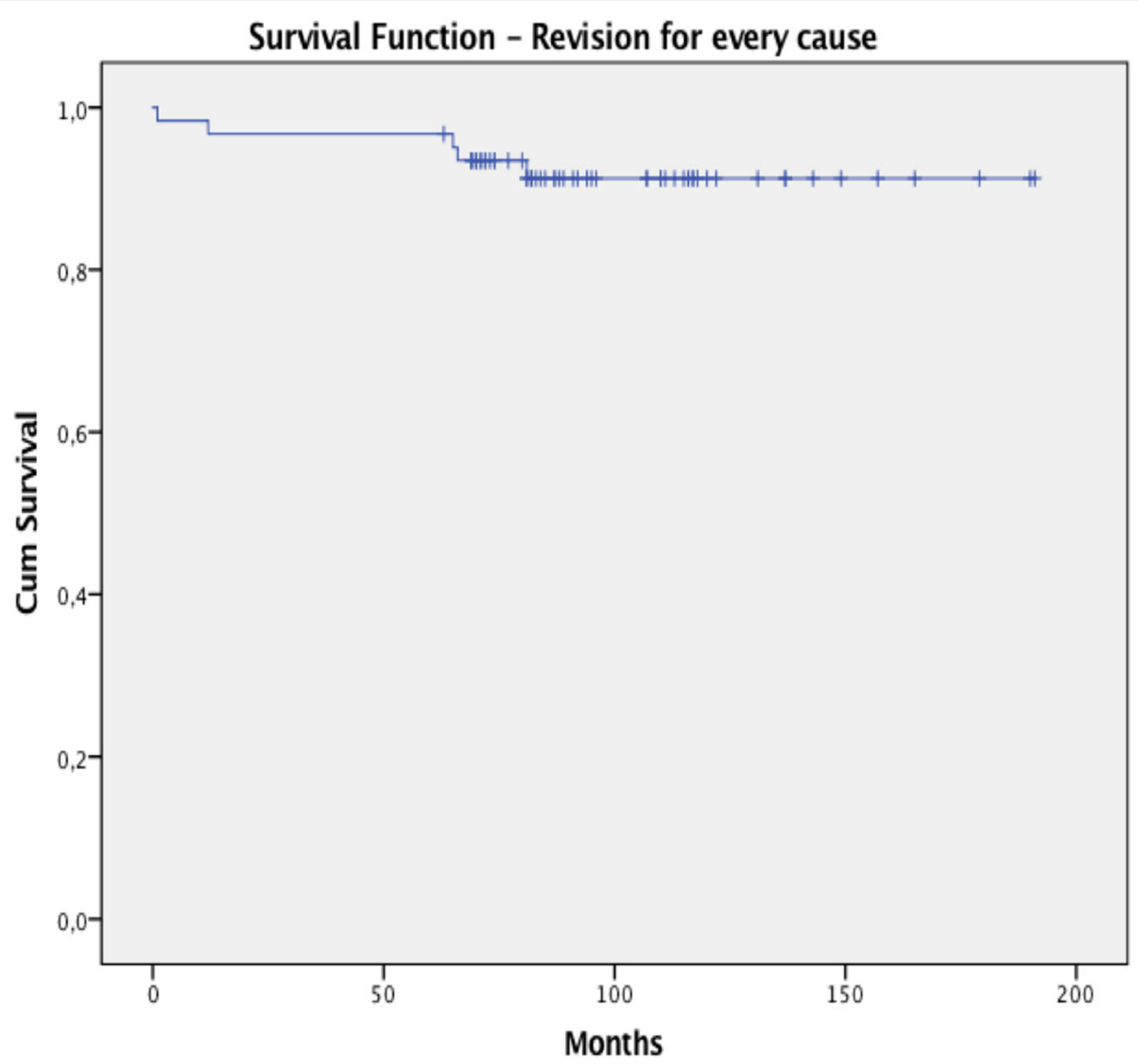

Fig. 4 Kaplan-Meier survival rate for revision for every cause

parameters may have contributed to the lower rate of dislocations in our series.

However, the modularity exposes to the risk of mechanical failure of the taper at the neck-stem junction; a high BMI, a high level of functional demand, a narrow medullary canal, and poor proximal bone support are factors that should be taken carefully under consideration when using a modular stem as they may influence negatively the outcomes of the revision procedure. Furthermore, one critical risk factor for the mechanical failure of the implant is fretting, which is defined as the damaging mechanical action that occurs when the contact components are subjected to cyclic loading, resulting in an oscillatory micro-movement [23]. It is, therefore, essential to ensure that there is a perfect placement of the Morse taper junction during the surgical procedure; the Revision stem used in our study provides a Morse taper to ensure the assembly of the distal and proximal elements, and a locking screw, as an additional safety tool for guaranteeing a stable connection of the two parts. Garbuz et al. [24] showed one stem fracture at the modular junction of 31 femoral revisions with a modular distal-fixation fluted tapered stem. This complication was also reported in association with monoblock stem designs intended for distal fixation [25]. In the patients included in our study, there was no mechanical failure of the femoral component; in particular, we did not report any complications in the stemneck junction, confirming the excellent resistance of the implant. We should also consider that patients undergoing revision surgery for femoral issues, are generally less demanding in terms of physical activity, and consequently the classical factors against modularity, such as high BMI, and/or large offset, play a minor role. The Kaplan-Meier survival analysis showed a good performance of the implant, with $88.1 \%$ survivorship after 81 months with complications for any reason as the endpoint, and $91.3 \%$ at 81 months with revision for any cause as the endpoint.

The average HHS of 71.9 points is a direct consequence of our population age and comorbidities. By the way, this finding is in line with those reported by Wirtz et al. [26], who published an improved HHS from a mean preoperative score of 37 points (range: 4-97; SD: 24) to 79 points (range: 4-100; SD: 19) at the last follow-up. We have noted a substantial increase of 35.4 points in the score from the preoperative to the postoperative time. 


\section{Limitations}

This study presents several limitations: The limitation of this study consists mainly on the retrospective design, limiting its scientific value. A second limitation is a high number of patients lost in follow up, which.

On the other hand, the validity is based on the long follow-up, showing with the final score reached, that this surgical solution is reliable.

\section{Conclusions}

The clinical results and mechanical stability obtained with this revision stem system are comparable with those observed with other designs of cementless revision stem. Our findings suggest that this stem is reliable in cases of periprosthetic femoral fractures, septic or aseptic stem loosening with femoral bone defects type IIIA and IIIB according to the Paprosky classification.

\section{Abbreviations}

THA: Total Hip Arthroplasty; HHS: Harris Hip Score

\section{Acknowledgements}

Go to the "Mario Boni Foundation" for the scientific support given to the paper.

\section{Authors' contributions}

All authors gave a substantial contribution to this study. L. P. was responsible for the whole study. SMP. R. contributed to write and revised the manuscript. F. collected and analyzed the data. E. J collected and analyzed the data. M. M. supervised the data collection and contributed to write the manuscript. F. B. performed the surgeries and supervised the whole study. All authors have read and approved the final version of the manuscript.

\section{Funding}

No funding was received for this study, The authors received no funding for this publication.

\section{Availability of data and materials}

The datasets used and/or analysed during the current study are available from the corresponding author on reasonable request.

\section{Ethics approval and consent to participate}

Required administrative permissions to access the raw data described in this study were granted by the institutional review board approval for this study, with protocol number 20140001445 at the Policlinico San Matteo Ethical Committee.

\section{Consent for publication}

Not applicable.

\section{Competing interests}

There are no competing interests for any of the authors.

\section{Author details}

${ }^{1}$ Sezione di Chirurgia Protesica ad Indirizzo Robotico - Unità di Traumatologia dello Sport, U.O. Ortopedia e Traumatologia Fondazione Poliambulanza, Via Bissolati 57, 25124 Brescia, Italy. ${ }^{2}$ Dipartimento dell'Anca e Traumatologico, IRCCS Policlinico San Donato, Milan, Italy. ${ }^{3}$ Clinica Ortopedica e Traumatologica, Fondazione IRCCS Policlinico San Matteo, P.le Golgi 19, Pavia, Italy. ${ }^{4}$ Università degli Studi di Pavia, Pavia, Italy.
Received: 31 May 2020 Accepted: 16 December 2020

Published online: 06 January 2021

\section{References}

1. Bozic KJ, Kurtz SM, Lau E, et al. The epidemiology of revision total hip arthroplasty in the United States. J Bone Jt Surg Ser A. 2009;91:128-33. https://doi.org/10.2106/JBJS.H.00155.

2. Kurtz $\mathrm{S}$, Ong K, Lau E, et al. Projections of primary and revision hip and knee Arthroplasty in the United States from 2005 to 2030. J Bone Jt Surg. 2007; 89:780. https://doi.org/10.2106/JBJS.F.00222.

3. Craig J Della Valle 1, Wayne G Paprosky The femur in revision total hip arthroplasty evaluation and classification. Clin Orthop Relat Res. 2004;(420): 55-62. https://doi.org/10.1097/00003086-200403000-00009.

4. Mayle RE Jr, Paprosky WG. Massive bone loss: allograft-prosthetic composites and beyond. J Bone Jt Surg Br Vol. 2012;94-B:61-4. https://doi. org/10.1302/0301-620X.94B11.30791.

5. Noble PC, Alexander JW, Lindahl LJ, Yew DT, Granberry WM, Tullos HS. The anatomic basis of femoral component design. Clin Orthop Relat Res. 1988; (235):148-65.

6. Mclnnis DP, Horne G, Devane PA. Femoral revision with a fluted, tapered, modular stem seventy patients followed for a mean of 3.9 years. J Arthroplast. 2006;21:372-80. https://doi.org/10.1016/j.arth.2005.08.022.

7. Rodriguez JA, Fada R, Murphy SB, et al. Two-year to five-year follow-up of femoral defects in femoral revision treated with the link MP modular stem. Arthroplast. 2009;24:751-8. https://doi.org/10.1016/j.arth.2008.09.011.

8. Weiss RJ, Beckman MO, Enocson A, et al. Minimum 5-year follow-up of a Cementless, modular, tapered stem in hip revision Arthroplasty. J Arthroplast. 2011;26:16-23. https://doi.org/10.1016/j.arth.2009.11.009.

9. Ibrahim DA, Fernando ND. Classifications in brief: the Paprosky classification of femoral bone loss. Clin Orthop Relat Res. 2017;475:917-21. https://doi. org/10.1007/s11999-016-5012-z.

10. WH HARRIS. Traumatic arthritis of the hip after dislocation and Acetabular fractures. J Bone Jt Surg. 1969;51:737-55. https://doi.org/10.2106/00004623196951040-00012.

11. Engh CA, Massin P, Suthers KE. Roentgenographic assessment of the biologic fixation of porous-surfaced femoral components. Clin Orthop Relat Res. 1990:107-28. https://doi.org/10.1097/00003086-199008000-00022.

12. Brooker A, Bowerman J, Robinson R, Riley LJ. Ectopic ossification following total hip replacement. Incidence and a method of classification. J Bone Jt Surg Am. 1973;55:1629-32.

13. Wirtz DC, Heller KD, Holzwarth U, et al. A modular femoral implant for uncemented stem revision in THR. Int Orthop. 2000:24:134-8.

14. Regis D, Sandri A, Bartolozzi P. Stem modularity alone is not effective in reducing dislocation rate in hip revision surgery. J Orthop Traumatol. 2009; 10:167-71. https://doi.org/10.1007/s10195-009-0076-0.

15. Cohn MR, Tetreault MW, Li J, et al. Is there a benefit to modularity for femoral revisions when using a splined, tapered titanium stem? J Arthroplast. 2020:4-9. https://doi.org/10.1016/j.arth.2019.12.041.

16. Regis D, Sandri A, Bonetti I, et al. Femoral revision with the Wagner tapered stem: a ten- to 15-year follow-up study. J Bone Jt Surg Ser B. 2011;93 B: 1320-6. https://doi.org/10.1302/0301-620X.93B10.25927.

17. Kwong LM, Miller AJ, Lubinus P. A modular distal fixation option for proximal bone loss in revision total hip arthroplasty: a 2- to 6-year follow-up study. J Arthroplast. 2003;18:94-7. https://doi.org/10.1054/arth.2003.50083.

18. Schuh A, Werber S, Holzwarth U, Zeiler G. Cementless modular hip revision arthroplasty using the MRP titan revision stem: outcome of 79 hips after an average of 4 years' follow-up. Arch Orthop Trauma Surg. 2004;124:306-9. https://doi.org/10.1007/s00402-004-0656-7.

19. Park YS, Moon YW, Lim SJ. Revision Total hip Arthroplasty using a fluted and tapered modular distal fixation stem with and without extended trochanteric osteotomy. J Arthroplast. 2007;22:993-9. https://doi.org/10. 1016/j.arth.2007.03.017

20. Sponer P, Kucera T, Urban K, et al. Osteointegration of an uncemented modular revision stem implanted during revision hip surgery. Acta Medica (Hradec Kral). 2014;57:105-11. https://doi.org/10.14712/18059694.2014.48.

21. Alberton GM, High WA, Morrey BF. Dislocation after revision total hip arthroplasty : an analysis of risk factors and treatment options. J Bone Joint Surg Am. 2002:84-A:1788-92.

22. Mahomed NN, Barrett JA, Katz JN, et al. Rates and outcomes of primary and revision total hip replacement in the United States medicare population. Bone Joint Surg Am. 2003;85-A:27-32. 
23. Mistry JB, Chughtai M, Elmallah RK, et al. Trunnionosis in total hip arthroplasty: a review. J Orthop Traumatol. 2016;17:1-6. https://doi.org/10. 1007/s10195-016-0391-1.

24. Garbuz DS, Toms A, Masri BA, Duncan CP. Improved outcome in femoral revision arthroplasty with tapered fluted modular titanium stems. Clin Orthop Relat Res. 2006;453:199-202.

25. Crowninshield RD, Maloney WJ, Wentz DH, Levine DL. The role of proximal femoral support in stress development within hip prostheses. Clin Orthop Relat Res. 2004;(420):176-80. https://doi.org/10.1097/00003086-20040300000024.

26. Wirtz DC, Gravius S, Ascherl R, et al. Uncemented femoral revision arthroplasty using a modular tapered, fluted titanium stem. Acta Orthop. 2014;85:562-9. https://doi.org/10.3109/17453674.2014.958809.

\section{Publisher's Note}

Springer Nature remains neutral with regard to jurisdictional claims in published maps and institutional affiliations.

Ready to submit your research? Choose BMC and benefit from:

- fast, convenient online submission

- thorough peer review by experienced researchers in your field

- rapid publication on acceptance

- support for research data, including large and complex data types

- gold Open Access which fosters wider collaboration and increased citations

- maximum visibility for your research: over $100 \mathrm{M}$ website views per year

At BMC, research is always in progress.

Learn more biomedcentral.com/submissions 